\title{
Riego en Chile colonial: mecanismos de apropiación, administración y resolución de conflictos por el uso de los sistemas hidrosociales del Valle Central
}

\author{
Pablo Camus Gayán ${ }^{1}$ \\ Sebastián Castillo Castillo \\ Enrique Muñoz Figueroa ${ }^{3}$
}

Recibido: 28 de enero de 2019 - Aprobado: 4 de abril de 2019

\begin{abstract}
Resumen
El riego, entendido como un sistema hidrosocial, fue uno de los pilares del desarrollo de la sociedad colonial chilena. El objetivo de esta propuesta es comprender las relaciones de poder y la organización económica y social articulada en torno a la apropiación y el uso de los sistemas de irrigación en el Valle Central de Chile. La metodología es cualitativa y se centró en analizar los mecanismos de apropiación, los sistemas de administración e instrumentos de resolución de conflictos. Las fuentes primarias estudiadas fueron las Actas del Cabildo de Santiago y los expedientes de juicios de la Real Audiencia, las cuales fueron complementadas con bibliografía secundaria. Este estudio es pertinente, pues representa una aproximación al conocimiento de las relaciones sociales y de justicia durante la Colonia, así como valida al riego como un objeto de estudio reciente que no ha sido abordado suficientemente por la historiografía latinoamericana.
\end{abstract}

Palabras clave: sistemas de agua, Chile colonial, burocracia, violencia

* Este artículo fue elaborado en el marco del proyecto "La tragedia de los comunes y la gestión del agua de riego en Chile: conflicto socio-ambiental y modelos de sustentabilidad", financiado por la Vicerrectoría de Investigación, Pontificia Universidad Católica de Chile y del Proyecto FONDECYT 1180537 " ¿Despotismo hidráulico? Irrigación, organización social y conflictos por el agua en una sociedad en transición al capitalismo. Valle Central de Chile. 1856-1914".

1 Chileno. Doctor en Historia, Pontificia Universidad Católica de Chile. Académico Instituto de Historia, Pontificia Universidad Católica de Chile. E-mail: pcamusg@uc.cl

2 Chileno. Licenciado en Historia, Pontificia Universidad Católica de Chile. E-mail: secastil@uc.cl

3 Chileno. Magister en Sociología (c), Pontificia Universidad Católica de Chile. E-mail: enmunfi@gmail.com 


\title{
Irrigation in Colonial Chile: Mechanisms of Appropriation, Management and Conflict Resolution for the Use of Hydrosocial Systems in the Central Valley
}

\begin{abstract}
Irrigation as a hydrosocial system was one of the pillars of development for colonial Chilean society. The purpose of this article is to understand power relations and the social and economic organization associated with the appropriation and use of irrigations systems in the Central Valley of Chile. The methodology used is qualitative and focused on analyzing the mechanisms of appropriation, management systems and instruments for conflict resolution. The primary sources studied were the Actas del Cabildo de Santiago meeting minutes and Real Audiencia case files, which were complemented with secondary bibliography. This study is pertinent as it represents a look at the knowledge of social relations and justice during colonial times and validates irrigation as a recent object of study that has not been sufficiently addressed by Latin American historiography.
\end{abstract}

Keywords: Water systems, colonial Chile, bureaucracy, violence

Contar con una provisión regular de agua ha sido objetivo fundamental de toda colectividad que se ha desenvuelto en nuestro planeta. En este estudio ilustramos la gestión de este recurso imprescindible a través del análisis de los mecanismos de apropiación, los sistemas de administración y los instrumentos de resolución de conflictos surgidos por su utilización en el Valle Central de Chile durante el periodo colonial. El objetivo principal de este trabajo es comprender cómo la apropiación y el uso de los sistemas hídricos han articulado las relaciones de poder y, a su vez, han definido la organización económica, social y cultural en un contexto histórico geográfico determinado. Para ampliar la mirada, la primera parte de este documento desarrolla un marco teórico que analiza los sistemas de agua y algunas de las formas en que las sociedades han usado o manipulado el recurso hídrico a lo largo del tiempo. Las particularidades de este vital elemento, así como de los sistemas de riego, su dimensión cultural y su relación física y social inmersa en el tiempo y el espacio, son algunos de los elementos que sostienen la argumentación de este articulo. El capítulo siguiente expone brevemente el sistema de riego del Valle Central chileno anterior a la época colonial, explica la obtención de mercedes de aguas para vecinos luego de la fundación de Santiago, analiza las funciones de las instituciones y autoridades encargadas de la administración de los sistemas de riego durante la Colonia, y los principales desafíos hídricos de la burocracia colonial. Mientras que la última sección analiza las distintas acciones que generaron conflictos sobre el uso de sistemas de agua como su apropiación y el bloqueo de paso, describe los argumentos de los actores interesados por el acceso al recurso hídrico y muestra las diferentes resolu- 
ciones de la Real Audiencia y las distintas respuestas de los protagonistas de los pleitos judiciales.

Se usó metodología cualitativa, basada en la transcripción, análisis e interpretación de fuentes primarias como los expedientes de juicios de la Real Audiencia y las Actas del Cabildo de Santiago. Estos acercamientos fueron complementados con bibliografía secundaria sobre los temas ya expuestos. De esta manera, este estudio representa un esfuerzo por visualizar el agua como un objeto de estudio histórico, materia aún pendiente para la historiografía, y que es pertinente dadas las discusiones actuales sobre su escasez, su gestión y su uso sustentable.

\section{Irrigación y sistemas de agua: una relación física y social inmersa en la historicidad}

El agua tiene la cualidad de ser dual materialmente, es decir, es universal -en tanto todas las sociedades la han necesitando y han hecho usufructo de ella-y particular -pues la forma en que las sociedades se han aproximado a ella cambia según sus circunstancias geográficas y sociales- (Tvedt, 2010). También es dual en su temporalidad, ya que tiene momentos de larga estabilidad (los ríos pueden seguir el mismo curso durante cientos de años), y, al mismo tiempo, inestabilidades aleatorias (un derrumbe, una sequía, entre otros) que pueden cambiar todo el sistema de manera irreversible. Su doble dualidad material (universal/particular) y temporal (estable/inestable) la dota de una historicidad única que no ha sido lo suficientemente explorada por los historiadores. De ahí que creemos en la pertinencia de este breve marco teórico a la problemática central, inspirados por la creencia de que "la historia medio-ambiental debería no solamente buscar un mejor entendimiento de como los humanos impactan en la naturaleza sino también como los diferentes medios ambientes crean diferentes posibilidades y restricciones para el desarrollo social" (Tvedt, 2010: 144) sin, por ello, caer en un determinismo.

En cuanto a la concepción del sistema de agua, Tvedt ha propuesto un marco epistemológico basado en tres niveles de análisis de la relación sociedad/naturaleza que son diferentes e interdependientes. El primer nivel es la forma física y el comportamiento del agua, en la medida en que es relevante para las sociedades. Esto incluye el ciclo de lluvias y las particularidades de los cursos de ríos. Su argumento es que el espacio físico y sus específicas diferencias son relevantes para el desarrollo histórico y los tipos de las prácticas sociales. El segundo nivel analítico concierne aspectos de la relación humanidad/agua, incluyendo las modificaciones actuales sobre el nivel físico del paisaje acuático y otros artefactos relacionados con el recurso 
hídrico. De esta manera, los sistemas de aguas no son solo físicos, sino también reflejan la habilidad y determinación de las sociedades para manipular o usar el agua a lo largo del tiempo; por ende, son artefactos materiales que influyen en el mundo material y cultural del agua. Finalmente, el tercer nivel es la dimensión institucional y conceptual del sistema de agua. Este incluye las prácticas de manejo del agua y los hábitos del pensamiento sobre ella y su control, el significado espiritual/religioso, y otras conceptualizaciones sobre el agua que se han desarrollado a lo largo del tiempo en diferentes contextos humanidad/agua.

La relevancia del sistema de agua es que permite superar el determinismo: "en vez de ver al ecosistema operando de acuerdo a ciertas leyes naturales o procesos, el concepto sistema de agua se enfoca en la relación entre naturaleza y agencia que quizás sea casual, accidental o ambos casos" (Tvedt, 2010: 148). Al enfocarse en los sistemas de agua, se hace la distinción entre los tiempos geográficos, sociales e individuales más complejos. La perspectiva del sistema del agua permite la integración tanto de la corta como de la larga duración, creando así nuevas estructuras. En consecuencia, el agua puede ser equiparada metafóricamente con el concepto filosófico de rizoma ${ }^{4}$, pues, al igual que el agua, "un rizoma no cesaría de conectar eslabones semióticos, organizaciones de poder, circunstancias relacionadas con las artes, las ciencias, las luchas sociales" (Deleuze y Guatarri, 2004: 13). La dimensión "rizomática" de las formas de apropiación del agua de las sociedades, consiste en que no logran nunca el equilibrio total o un estado de perfección, sino que son eminentemente históricas (Banister, 2014).

Dada esta historicidad única del agua, nuestra premisa es que las formas de apropiación y uso de los sistemas del agua internalizan las relaciones sociales del contexto histórico específico. Historiográficamente, el riego, entendido como un sistema de agua, es un campo de estudio reciente y que tiene mucho potencial en tanto ha sido tratado por antropólogos y geógrafos, pero poco por historiadores (Palerm, 1995), siendo la excepción los historiadores mesoamericanistas en el ámbito latinoamericano. Estas diferencias son más considerables si recordamos que existen más de un millón de sistemas de riego, conociéndose con precisión apenas unos doscientos (Hunt, 2007). Asimismo, en el análisis del riego existen una serie de categorías contrapuestas como comunal/burocrático o micro/macro impuestas por Karl Wittfogel y continuadas hasta por sus críticos como Arthur Mass.

En este artículo seguimos la intuición fundamental de Despotismo Oriental de Wittfogel (Wittfogel, 1966), que es estudiar la interconexión 
entre el sistema político, infraestructuras del agua y las formas de riego (Vidal-Niquet, 1964), pero sin intentar defender la hipótesis hidráulica de Wittfogel ni su estructuralismo de inspiración marxista. Mass enriqueció el estudio de los sistemas del agua al incorporar la dimensión de los individuos. Esto posibilitó epistemológicamente una comprensión de la dinámica transformadora de los sistemas de riego en relación con la organización social, sus actores y el papel del poder (Palerm, 1995). Susan Lees critica ambos modelos, porque presuponen que el conflicto es inevitable a la distribución del agua; según ella, esto es un mito antropológico desmentido por casos concretos en el que la escasez de agua no implica necesariamente enfrentamiento (Lees, 1989).

La cara contrapuesta al Despotismo Oriental es Elixir: A Human History of Water, en el que se hace un estudio global de algunos de los sistemas de riego precapitalistas más emblemáticos de la historia humana, para rescatar experiencias a nivel micro. Sus conclusiones se resumen en las diferencias de perdurabilidad entre los sistemas de riego de pequeña y gran escala. Los primeros tienen mayor flexibilidad histórica al ser sustentables con su medio ambiente, garantizándose que sean perdurables en el tiempo, incluso algunos hasta el presente. Mientras que los grandes sistemas de irrigación tienden a ser de duración limitada. Es alarmante que nuestro consumo de agua comparta algunas características generales con los grandes sistemas de riego fallidos, especialmente aquellos con tendencia a la mercantilización de todos los aspectos del agua y con carencia de mecanismos que regulen el agua como un bien común. Pese a las críticas y a las mutaciones de la historiografía desde que Karl Wittfogel introdujo el problema del riego, el peso epistemológico de su obra sigue siendo visible hasta nuestros días, ya que pareciera no ser deseable salir del esquema de las conexiones entre los sistemas de riego, las infraestructuras del agua y el poder político (Bichsel, 2016).

En suma, parece necesario explicar ciertos conceptos e infraestructuras relacionadas al tema de este documento. Por "irrigación" entenderemos el movimiento de agua dulce de un punto a otro, movimiento hecho por el artificio humano para que el agua llegue a lugares donde no iría en condiciones naturales. Así, uno de los factores fundamentales al controlar el agua es su flujo, que puede variar entre la escasez y sobreabundancia (Hunt, 2007). Todo sistema de irrigación esta compuesto por una instalación, como una puerta o toma, que captura el canal y lo aleja de su curso natural de descenso; por otra parte, el control posterior (canales, compuertas, campos) guía el flujo de agua de la superficie del campo hasta que el agua se absorba o fluya en la superficie fuera de las obras de control (Hunt, 1988). La construcción de sistemas de riego requiere de un gran costo económico y social; además, depende de las tecnologías del momento y de las posibilidades de inversión. Una vez instalado, el sistema requiere mantención constantemente, 
conllevando un nivel de compromiso social a largo plazo entre quienes son afectados directamente y una definición de roles y tareas específicas, lo que Erica Nathan denomina como flujo social del agua (Nathan, 2007: 272). Todas estas asignaciones son fundamentales en los sistemas de riego, sobre todo en aquellos que son masivos pero no centralizados, como Bali (Fagan, 2012: 416).

La legitimidad de los sistemas de riego en general es doble: interna y externa. La legitimidad interna se da entre los miembros de las comunidades responsables de la construcción y mantención, mientras que la externa depende de una entidad ajena a las comunidades. Entonces, resulta plausible que sistemas de riego de microescala estén ligados a dominios de poder más altos como el Estado, de manera tal que generen sistemas de gestión de agua a gran escala sin necesariamente caer en la tesis hidráulica. Von Benda-Beckmann (2007) establece el concepto de pluralismo legal del agua, que combina las distintas escalas de legitimidad que se entrecruzan desde lo local a lo estatal (Kelly, 1983), y que se basaría en el fenómeno distintivo del agua como elemento "rizomático" que puede cumplir múltiples funciones - desde lo religioso, pasando también por lo político y lo económico.

\section{Apropiación y administración de los sistemas de riego del Valle Central de Chile en el periodo colonial}

Contrarias a las apreciaciones del historiador Benjamín Vicuña Mackenna en su decimonónico libro El Clima de Chile, investigaciones recientes han indicado que las huestes indianas del conquistador Pedro de Valdivia que arribaron al valle del Maipo se encontraron con un territorio bastante poblado, que contaba con un sistema de regadío originado hacia el año 900 d.C., gracias al desarrollo de la cultura Aconcagua en el periodo agroalfarero tardío (Falabella et al., 2016: 744). Mario Góngora reveló que en el proceso contra Pedro de Valdivia en Perú durante 1549, este señaló que "las tierras de sembraduras se daban a una legua o legua y media de la ciudad" (Góngora, 1970: 243). Por otra parte, Armando de Ramón identificó, en el actual territorio de la Región Metropolitana de Santiago, tres acequias que extraían agua del río Mapocho. La acequia de Ñuñoa, llamada también de Apoquindo o Tobalaba, regaba los campos al pie de los Andes hasta Macul. La acequia de Vitacura tenía su bocatoma cerca de la desembocadura del estero Arrayán con el río Mapocho y se prolongaba orillando el cerro San Cristóbal, para luego caer en cascada o "salto" y formar un cauce madre del cual se desprendían muchas acequias menores que regaban los campos de Conchalí, Huechuraba y Quilicura. Mientras que al poniente estaba la acequia de Apochame que regaba el sector conocido actualmente como Cerrillos, 
aun cuando esto último ha sido rebatido por Stenberg y Sotomayor, quienes han considerado que la bocatoma de esta acequia se ubicaba al oriente -aparentemente en La Dehesa-, y seguía su curso por el pie de monte de la cordillera, en las actuales comunas de Providencia, La Reina, Peñalolén y Macul. Además, estos autores plantearon la existencia de otra acequia que tenía su bocatoma en el río Mapocho, en el sector sur oriente del cerro San Cristóbal, que regaba los campos de Renca. Hacia el sur, en el río Maipo se habrían desprendido otra serie de acequias que regaban los campos fértiles de Isla de Maipo, Lonquén, Malloco, Tango, Talagante y Peñaflor (De Ramón, 2000; Stenberg y Sotomayor, 2012).

La antigüedad de los sistemas de riego fue percibida por algunos actores del Valle Central durante la Colonia. Si bien estas son valoraciones que no pueden ser precisadas temporalmente, son una aproximación a la idea que los orígenes de algunas acequias disputadas durante la Colonia fueron anteriores al siglo XVI. El señor Manuel Ramírez respondió una acusación de Juan Baptista de las Cuevas sobre la abertura de una bocatoma en un predio de Tilcoco, aludiendo que aquella instalación "no es nueva, sino tanta antigua [sic] que no hay hombre en todo aquel partido que haga memoria de su apertura como protesto justificar" (Real Audiencia, vol. 691: fj. 17). Por su parte, Domingo Mathias Frías fue notificado en 1775 por el Cabildo de San Juan de la Frontera para que mudase una acequia que regaba su propiedad; Frías respondió que dicho canal "hace según tradición más de dos siglos de años que tiene su curso por donde actualmente corre" (Real Audiencia, vol. 691: fj. 18).

Una de las primeras fuentes de legitimidad de los conquistadores frente a la monarquía fue la aplicación del derecho castellano a través del Fuero Juzgo, el Fuero de Castilla, el Fuero Real y el Código de las Siete Partidas. Estas disposiciones legales, paradójicamente, fortalecían el control monárquico del agua en desmedro del poder local representado por las municipalidades, al declarar que ciertos aprovechamientos de agua dulce eran regalías monárquicas (Stewart, 1970). No obstante, lejos de la autoridad central, especialmente en los inicios de la conquista y en el lejano Chile, las huestes indianas ejercieron su poder a través del Cabildo y otras instancias, e intentaron generar sus propias formas de control en relación al uso del agua de riego. Según Mario Góngora, Chile es un marcado ejemplo del tipo de gobernación militar distante del control administrativo virreinal (Góngora y Borde, 1956). Por otra parte, los diferentes códigos del derecho castellano contuvieron normas distintas, algunas de ellas contradictorias, excluyentes y difíciles de interpretar, sobre todo ante la falta de juristas competentes. Al mismo tiempo, la tradición jurídica española daba una importancia relevante a la costumbre por sobre la ley escrita, por lo que fue muy común que en el uso y reparto del agua se procediera de una manera casuística (Von Wobeser, 1993). 
Por ejemplo, de acuerdo a la tradición jurídica castellana, el Derecho Indiano estableció "que los pastos, montes y aguas sean comunes en las indias... mandamos, que el uso de todos los pastos, montes y aguas de las provincias de las indias sean común a todos los vecinos de ellas" (Zamora, 1844: 165). Sin embargo, los vecinos eran, precisamente, los miembros de las huestes indianas vencedoras, quienes establecieron las acequias como limites de sus propiedades, y se otorgaron mercedes y derechos de uso del agua dulce de rápido acceso, a pesar de los apoyos jurídicos otorgados por la corona a los nativos, que aseguraban al indio de pueblo o estancia el pleno derecho al goce de agua para riego (Silva, 1962: 266). En este sentido, uno de los intereses principales de este trabajo es analizar los mecanismos de apropiación y administración de los recursos productivos, en este caso, las acequias del Valle Central colonial y el agua que corre por ellas. Esto representa un esfuerzo por seguir la interpretación de Mario Góngora, quien planteó que la investigación debía centrarse más en las "fuentes que nos transmiten la aplicación del derecho a casos concretos" que en el ámbito jurídico en cuanto tal. En efecto, Góngora sugirió la "importancia capital de conocer las formas de cumplimiento y sobre todo de incumplimiento de las leyes para llegar al derecho efectivamente vivido" (Góngora, 1970: 273).

En cuanto a la confusión jurídica generada por las múltiples fuentes del derecho castellano, se puede inferir, de acuerdo con Antonio Dougnac y Javier Barrientos, que los bienes de realengo o monárquicos como las aguas daban a la corona un "dominio eminente" sobre ellas y, al mismo tiempo, la autoridad y libertad para entregarlas al uso de particulares, mediante mercedes otorgadas operativamente por el Gobernador y por el Cabildo, cuestión que, al menos para el siglo XVI, está consignada en las Actas del Cabildo de Santiago (Dougnac y Barrientos, 1991). Los riesgos asumidos por los jefes de conquista y sus huestes fueron recompensados con prodigas mercedes de tierras y de aguas, además de encomiendas de indios. El control de las acequias era uno de los premios a repartir más deseados tras una empresa de conquista exitosa, pues era el único medio que aseguraba la supervivencia y permanencia en aquellos parajes remotos. La importancia de la administración de sistemas de agua fue significativa desde los albores de Santiago a través de su Cabildo, institución que elaboraba las ordenanzas referidas a la entrega de mercedes de aguas y a las prohibiciones referentes al mal uso y adulteración de las acequias de la ciudad, así como también designaba a una persona dedicada a distribuir el uso de las usas y vigilar el cumplimiento de las normativas hídricas y el cauce natural de las aguas: el alarife.

Martín Sánchez-Rodríguez ha estudiado la olvidada dimensión social del agua en la época colonial dentro de las ciudades desde sus fundaciones. Mediante el uso de la cartografía de la ciudad de Santiago, desplegó la red 
de acequias de la ciudad. Contrario de la tesis urbanista "ovandista", que presupuso la configuración de la ciudad colonial determinada por elementos del plano de Ovando en Santo Domingo (como el plano damero y la plaza central con las instituciones de la corona, entre otros), el autor demostró el "elemento hidráulico como componente principal y característico del urbanismo de Santiago de Chile y de otras poblaciones que destacan por la presencia notable de la red de conducción de agua a través de acequias" (Sánchez-Rodríguez, 2015: 42). En consecuencia, uno de los intereses fundamentales del Cabildo de Santiago, desde la década de 1540, fue velar por la inalterabilidad de los cursos hídricos de las acequias, la cual podía estar amenazada por intereses de terceras personas sin acceso formal a ellos. La inflexibilidad de la normativa fue clara, en cuanto prohibió tapar, entorpecer o desviar el flujo de las acequias, pues estipuló que toda persona, independiente de su posición social en la ciudad, a excepción del alarife, no tenía facultad alguna para alterar la red de canales de Santiago (Actas del Cabildo de Santiago, 13-VIII-1548). Además, este mandato castigó en forma severa tanto al ejecutante de la falta -indio o esclavo- con azotes en la plaza, como al autor intelectual del delito -amo o señor-con una multa económica proporcional a la cantidad de veces en que incurriera en la infracción y con pena de cárcel de haber reincidencia. A fines de la década de 1940, el Cabildo de Santiago nombró a Lorenzo Núñez como alarife, con el objeto de aplicar las penas que recayeran en las personas que trasgredieran las ordenanzas de aguas. En uno de aquellos ordenamientos se indicó que ningún vecino o persona podía, por ningún motivo,

"quebrantar las aguas de como el dicho alarife las marcare, quitando de una acequia ni echando en otra, en ninguna vía ni marca que sea, so pena, por cada vez que lo tal se viere e hallare, pague cinco pesos de oro para las obras públicas de esta ciudad; y el yanacona o esclavo que fuere tomado, le serán dados cien azotes como a público ladrón" (Actas del Cabildo de Santiago, 25-X-1549).

Diez años después de la fundación de Santiago, en 1551, la cuestión del agua seguía siendo fundamental. En aquella oportunidad, el Cabildo de la ciudad, encabezado por el "mui magnifico señor Rodrigo de Quiroga", consideró que era conveniente que

"haya una persona alarife, e tenga cargos de agua, por la mucha necesidad que hay de repartir e dar a las personas que tienen chácaras e tierras, a cada uno lo que cupiere e porque vos, Pedro de Gamboa que estáis presente en el dicho cabildo, sois persona que se os entiende en repartir las dichas aguas: os cometemos para que podáis usar y ejercer el dicho oficio de alarife por tiempo y espacio de un año cumplido, primero siguiente, que se cuenta desde hoy día en adelante hasta ser cumplido, por precio e cuantía de doscientos 
pesos de buen oro, que nos obligamos de daros" (Actas del Cabildo de Santiago, 22-XII-1551).

El acta de nombramiento de Pedro de Gamboa de 1551 comprueba que el alarife no solo tenía como función principal la marcación de las acequias y tajamares de la ciudad, sino también administrar y repartir cargos de agua. Esta labor surgió a raíz de la necesidad de los vecinos de la ciudad por contar con aprovisionamiento hídrico seguro para sus tierras y chacras, lo cual pudo ser indicio de un crecimiento de la cantidad de población de Santiago entre 1541 y 1551, o de un incremento de la demanda por terrenos productivos que requirieren de un mayor volumen de agua, entre otras hipótesis. El aseguramiento del suministro de riego para las propiedades de los vecinos también fue preocupación del Cabildo en 1553. Los miembros de esta institución limitaron los lugares en los que podían vivir los indios y yanaconas en las alturas de la ciudad, para evitar oposiciones a los pasos hídricos que surtían a la ciudad. El Cabildo exigió que los vecinos a cargo de los indios tenían que mudarlos hacia otro sitio dentro de un plazo determinado; en caso contrario, debían cancelar una multa pecuniaria (Actas del Cabildo de Santiago, 1-VII-1553).

Las capitulaciones celebradas entre la corona y los conquistadores facultaron a los lideres de las empresas de conquista otorgar una serie de beneficios, tales como mercedes de tierras y aguas. Sin embargo, de acuerdo a los procedimientos contemplados en las Ordenanzas de nuevos descubrimientos y poblaciones de 1573, el poder monárquico buscó encausar la conquista dentro de límites jurídicos metropolitanos y asentar su poder en las tierras descubiertas. En definitiva, las nuevas normativas reflejaron el origen del Chile colonial. En 1602, la mensura de Gines de Lillo delineó las propiedades en terrenos y legitimó legalmente el otorgamiento de los derechos de aguas y tierras otorgados durante el periodo de conquista. Un ejemplo de la redacción del otorgamiento de estos derechos, conservado hasta nuestros días, es el siguiente:

"en nombre de Su Majestad y como su gobernador y capitán general en este dicho reino; y como de derecho mejor puedo y debo, hago merced al dicho capitán Fernando Álvarez de Bahamonde de las dichas doscientas cuadras de tierras de largo en la parte y lugar de suso referidas, y cincuenta en ancho, para que Sean suyas y de sus herederos y subcesores, presentes y por venir, con sus entradas y salidas, aguas y corrientes, para que se pueda aprovechar de ellas, como de bienes suyos propios, ganados y adquiridos en el real servicio" (de Lillo, 1605: 20).

El sello distintivo de la entrega de mercedes de tierras y aguas desde comienzos del siglo XVII fue la referencia al Monarca español como otorgador 
legítimo de dichos derechos a través de sus representantes en el Reino -el Gobernador, en este caso. Esto se mantuvo durante todo el periodo colonial, pues las autoridades e instituciones que deliberaron, denegaron y entregaron dichas mercedes, lo hicieron a nombre del monarca en ejercicio. El control metropolitano fue reafirmado en el año 1609 por medio de la aprobación de las Ordenanzas de la Real Audiencia de Santiago, ya que este cuerpo legal otorgó al Gobernador y Real Audiencia la facultad de entregar cuadras de tierras con sus respectivos sistemas de aguas. Este ordenamiento estableció que las peticiones para repartir las aguas y las tierras se presentasen ante el Gobernador, quien debía remitirlas al Cabildo, lugar donde se discutía la pertinencia de la solicitud. Dougnac y Barrientos citaron la Ordenanza 57, que mandaba que "cuando al presidente y oidores hubieren de repartir las tierras, aguas, o abrevaderos, o pastos de alguna ciudad, villa o lugar entre las personas que las fueren a poblar lo hagan al parecer de los cabildos de ellas" (Dougnac y Barrientos, 1991).

El Cabildo fue un espacio de exposición, discusión y deliberación sobre temas cotidianos de los sistemas de riego. Así, esta institución consistorial exigió a los vecinos que se preocupasen por el mantenimiento de acequias y otros pasos de agua, estableciendo condiciones, plazos y castigos para cada caso particular. Por ejemplo, en una sesión de noviembre de 1748, dicha casa edilicia ordenó a los vecinos de la cuadra de abajo del Cabildo que limpiasen una acequia y bocacalle dentro de siete días, pues se habían llenado de arena por la venida del río y la limpia anterior había sido hecha por el ayuntamiento; en caso no de no cumplir con el mandato, los vecinos iban a ser apercibidos con una multa (Actas del Cabildo de Santiago, 8-XI-1748). Junto con esta labor de mantenimiento, la institución vecinal fue la encargada de validar las mercedes de toma de aguas otorgadas por el gobernador, y llevar el registro definitivo de todas ellas en los libros del ayuntamiento; para ello, el poseedor del título debía presentarlo en una sesión del Cabildo, luego éste autorizaba la ley y la merced era anotada en los ejemplares del Cabildo por el escribano (Actas del Cabildo de Santiago, 10-XI-1729). Asimismo, este organismo consistorial aconsejaba al gobernador respecto del otorgamiento de permisos para uso de acequias y bocatomas. En 1778, el Cabildo puso en consideración al gobernador respecto de los inconvenientes de conceder licencia a los señores Blas Gonzáles y José Antonio Frías para sacar dos bocatomas desde el río con sus respectivas acequias, pues esto atentaría contra la condición común del río y se encontraban bajo un periodo de necesidad manifiesta de agua que podía originar contiendas y robos de aguas (Actas del Cabildo de Santiago, 11-XII-1778).

Mientras tanto, el Gobernador desempeñó un rol fundamental en el otorgamiento de mercedes de aguas y en el mantenimiento de la red hídrica, tanto de manera autónoma como en colaboración con otras instituciones 
y autoridades. En cuanto representante del Rey en dominios indianos, el gobernador dio títulos y mercedes de tomas de agua, como el caso del licenciado Francisco Ruíz, que acudió al Cabildo con sus posesiones de aguas dadas por el Gobernador Gabriel Cano y Aponte, con el fin que el recinto consistorial registrara sus dominios en las actas oficiales (Actas del Cabildo de Santiago, 10-XI-1729).

Hubo autoridades con atribuciones más restringidas que las del Gobernador y el Cabildo, pues no estaban facultados para otorgar o registrar derechos de agua. Entre ellos se encontraban el Corregidor, el Procurador General y el Alcalde Mayor de Aguas. Ellos se preocuparon por la provisión de agua segura y regular, lo que garantizó la legitimidad interna del sistema; por tanto fueron parte fundamental de la red hidrosocial. Entonces, la limpieza periódica de las acequias y los canales era fundamental para la mantención de los sistemas de riego de la ciudad, actividad realizada con recursos del ayuntamiento o a cargo de los propios vecinos con mercedes de aguas, previo mandato público del Cabildo y Gobernación. Los particulares que no acatasen la orden de limpieza, eran apercibidos por el edificio consistorial y debían cancelar una multa. La finalidad de la sanción económica fue desalentar las conductas que apremiasen el funcionamiento correcto de la red hídrica, tales como el no aseo de acequias, canales y acueductos, tapar el paso de agua o provocar derrames de aguas en calles y caminos públicos, entre otras.

El Corregidor se preocupó por la provisión del recurso hídrico, desplegando recursos propios para tales labores, y aconsejando y trabajando en conjunto con otras autoridades. En una sesión del Cabildo, el Corregidor expuso la necesidad de sacar agua desde el río Maipo, a causa de la falta de lluvias, la carencia de agua de los hacendados de Chuchunco y Renca, y los extravíos de aguas hechos desde las acequias del pago de Nunñoa (Actas del Cabildo de Santiago, 8-VI-1742). La preocupación del Corregidor fue la vigilancia de la correcta provisión de agua, a través de la denuncia de los robos de agua en sitios geográficamente riesgosos de los que podían temerse desgracias y muertes, como el pago de Ñuñoa, y la designación de cuidadores de acequias a cambio de un salario. En la sesión de Cabildo del 31 de octubre de 1729, dicho funcionario real dispuso de guardias en las tomas de las acequias para que los vecinos con derechos de aguas no tapasen el cauce del río (Actas del Cabildo de Santiago, 31-X-1729).

El Procurador General tendió puentes entre el Cabildo -en tanto institución que acordaba y decretaba resoluciones relativas al uso de los flujos de agua-, y otros estamentos que debían autorizar o rechazar dichas disposiciones comunales. El Cabildo de Santiago determinó, en una sesión de junio de 1742, que el Procurador General de Santiago debía presentarse ante los señores de la Junta de Balanza, para presentar una Real Cédula de 1738 que acordó extraer agua del río Maipo y así impregnar el costo 
de las obras al ramo de Balanza para proyectos de obras públicas (Actas del Cabildo de Santiago, 8-VI-1742). Sin embargo, la labor del Procurador General sobre los sistemas de riego se limitó solo a informar solicitudes y determinaciones, pues no estuvo facultado para realizar otras funciones. Dada la imposibilidad de que los encargados de recaudación de impuestos para la apertura del Canal San Carlos siguiesen realizando sus funciones en 1802, el Procurador General de Santiago no podía reemplazarlos en esas tareas, por lo que informó esa limitación a la comisión del Cabildo y propuso a otro funcionario más idóneo: el Alcalde Mayor de Aguas (Actas del Cabildo de Santiago, 3-XII-1802).

En términos generales, este Alcalde veló por el cumplimiento de los mandatos hechos por el Gobernador y el Cabildo. Entre ellos estuvieron, por ejemplo, el cobro de recursos adeudados por particulares interesados en nueva infraestructura hídrica y la clausura y vigilancia de albañales y acequias para evitar robos de agua. Para todo esto el Alcalde de Aguas era auxiliado por tenientes que cumplían sus labores con celeridad y dedicación. En cuanto al ámbito administrativo, el Juez de Aguas se encargó de solicitar pagos de costos a vecinos beneficiados por nuevas obras hídricas, como en 1772, cuando un juez recaudó los montos restantes para la dotación de agua en el Curato de San Isidro (Actas del Cabildo de Santiago, 6-XI1772). Otra función de este juez durante la Colonia fue distribuir aguas sobrantes que corrían por las aguadas, previo mandato del Cabildo. Por ejemplo, esta institución comunal facultó al Juez de Aguas para distribuir, a su conveniencia, el excedente resultante del pilón de la plazuela de San Isidro, sin que aquello perjudicase el estado de la vía pública (Actas del Cabildo de Santiago, 6-XI-1772).

La vigilancia de las infraestructuras para la conducción del agua fue una medida concebida para mantener el buen uso de los sistemas hídricos coloniales. Esta observación fue efectuada por guardias contratados por el ayuntamiento a cambio de un pago, o por chacareros, peones o sirvientes de los señores que poseían mercedes de agua. Las tomas de las acequias eran vigiladas, pues desde ellas podía extraerse el vital elemento. Por otra parte, las ordenanzas, cuerpos legales que regían el buen gobierno de la ciudad, consignaron las disposiciones dictadas por las instituciones y autoridades encargadas de la administración del agua colonial, las cuales eran estimadas como convenientes para la provisión de la población. El Cabildo fundamentó la decisión del Alcalde de Aguas de Santiago Luis Manuel de Zañartu, previa orden del Gobernador, de tapar los albañales de la ciudad, citando las ordenanzas veinticuatro y veinticinco que "prohibió[eron] con varias penas no se sacase ni derramase por las calles el agua de las acequias madres, y que para esto se construyesen de cal y ladrillo, o de cal y piedra" (Actas del Cabildo de Santiago, 31-III-1761). 
En este sentido, es interesante analizar la servidumbre de acueducto en la administración del agua dulce, por tratarse de una fuente de continuos conflictos resueltos por las instituciones desde arriba, no por sus funcionarios. Es menester recordar que, históricamente, el ser humano se ha enfrentado a los siguientes problemas sobre uso del agua: los derechos de paso, el sistema de reparto y las respuestas a las situaciones de escasez. Esto había ocurrido históricamente en España, donde el riego artificial ha sido necesario para el cultivo de productos agrícolas. El derecho indiano reconoció la existencia de varias servidumbres relativas al uso de las aguas como las "rústicas", de las cuales las más comunes eran las de acueducto y abrevadero. La de acueducto era el derecho a conducir agua por fundo ajeno, derecho que le permitía a su titular construir, mantener, reparar, limpiar y conservar la acequia por donde escurrían las aguas (Muñoz, 2000). No obstante, la revitalización o el trazado de nuevas acequias de riego no se halló al arbitrio de los interesados, pues varias ordenanzas indicaron que era el Cabildo el que otorgaba la autorización para fijar el curso de los cauces y las nuevas aperturas. Del mismo modo, especialmente en tiempos de escasez por sequía, se estableció que las mercedes de riego debían ser utilizadas por sus beneficiarios según un sistema de turnos que permitiera el mejor aprovechamiento de las aguas (Dougnac y Barrientos, 1991). Con la consolidación de los asentamientos españoles en el Chile colonial, los conflictos inherentes a las características "rizomaticas" del agua vistas supra fueron in crescendo, especialmente a partir del siglo XVIII. Analizaremos algunos de ellos en el siguiente capítulo.

\section{Origen, manifestaciones, argumentos y resoluciones de algunos conflictos por el agua en el Valle Central colonial}

Si en el capítulo anterior estudiamos el nivel institucional del sistema de aguas, analizar conflictos entre actores no institucionales nos servirá para adentrarnos en una dimensión microhistórica, de tal manera que podremos determinar las formas de uso del agua. Este objetivo se hará mediante el estudio del derecho efectivamente vivido, como sugirió Góngora (1970), a través del análisis de los documentos del Cabildo de Santiago y de la Real Audiencia, pues el poder monárquico dejó en manos de estas dos instituciones la resolución de las disputas por el agua de riego. El Cabildo fue la primera instancia para resolver estos pleitos entre vecinos, eligiendo anualmente a un Juez de Aguas que estudiaba cada caso y emitía un fallo. Sin embargo, no ha quedado un registro escrito del desarrollo de estos juicios, al ser eminentemente orales. Por su parte, la Real Audiencia dirimió conflictos que no eran resueltos por el Juez de Aguas, así como también recibía las apelaciones de los fallos de primera instancia. Sus expedientes contienen los pleitos 
judiciales entre particulares que disputaban el uso de una fuente hídrica, así como los móviles, argumentos e intereses que fundamentaban las demandas por derechos de agua. La Real Audiencia, a diferencia del Cabildo, archivó los pleitos judiciales, algunos de los cuales están conservados hasta hoy en el Fondo Real Audiencia del Archivo Nacional de Chile. Este registro fue un requerimiento del sistema judicial colonial, ya que se configuró como una herramienta para la mantención del orden jurídico y social preestablecido (Agüero, 2006: 26).

\section{Las luchas por el agua}

Unos cuarenta litigios por derechos de aguas fueron encontrados en los fondos del Archivo Nacional de Chile, los cuales fueron analizados durante nuestra investigación. Más de la mitad de los casos analizados ocurrieron en el siglo XVIII, mientras que un poco más del 10\% de estos fueron del siglo XVII y cerca del $20 \%$ del total se produjeron dentro de las tres primeras décadas del siglo XIX. En cuanto a la espacialidad de los conflictos, estos se concentraron en la actual zona central de Chile, a excepción de tres casos ocurridos en Copiapó, Coquimbo y San Juan de la Frontera. Algunos de los sitios en los que hubo litigios por el agua fueron Casablanca, Polpaico, Renca, Huechuraba, Santiago, Melipilla, Chuchunco, Rancagua, Colchagua y Vichuquén.

Estos conflictos del Valle Central durante la Colonia están relacionados, en su mayoría, con derechos de uso de acequia, paso por otra propiedad, servidumbre de agua y de uso de regadores, entre otros. Los tipos de propiedades que usaban o pretendían aguas eran las haciendas o una parte de ellas, estancias, chacras, chacarillas, y solares; por su parte, algunos usos que los actores implicados en los conflictos dieron o desearon dar al agua fueron el consumo humano y animal, el riego de viñas, arboledas y plantas, la cosecha de productos agrícolas como frutos y alfalfa, o el dar fuerza motriz a molinos. En relación con estos juicios, diecinueve son casos litigados por hombres y veinte por mujeres, muchas de ellas viudas o herederas. Los pleitos judiciales entre hombres eran originados por conflictos de derechos de aguas, usurpaciones y oposiciones al paso de aguas, siendo ambos propietarios de terrenos, por lo que se buscaba dilucidar quién o quiénes podían hacer uso formal del recurso hídrico. Generalmente, los casos litigados por mujeres fueron iniciados fundamentalmente por viudas o mujeres solteras, en un contexto de muerte del padre de familia.

Gracias al análisis de los expedientes del fondo de Real Audiencia, se propone un cuadro general de los mecanismos de apropiación y bloqueo del agua en el Chile colonial. Se plantea que uno de los problemas fundamentales del derecho hídrico colonial en el Valle Central de Chile fue la 
conducción del agua por propiedades ajenas. Muchas chacras y terrenos no necesariamente gozaban de un cauce adyacente para proveerse, por lo que requerían de un acueducto, es decir, un canal que condujese el agua desde el cauce principal hacia una propiedad sin una fuente natural directa. El terreno por el que pasaba una fuente hídrica y abastecía a otros que no poseían un cauce adyacente se llamó "predio dominante y sirviente de agua". Esta limitación geográfica fue una fuente constante de conflicto entre dueños de predios con acceso a cauces naturales y propietarios sin acceso a ellos. Cayetano Fontecilla demandó a Francisco Javier Errázuriz por usurpar una acequia, con el fin de regar una viña con agua que pasaba por el predio del demandante. Errázuriz aseveró que "el pasar una acequia por el predio [...] no da derecho a usar de ella", argumento que muestra la percepción de que el derecho de uso de agua era independiente a la posesión de un bien raíz (Real Audiencia, vol. 755: fj. 59v).

La apropiación y despojo del agua conllevó la perpetración de un acto violento que afectó las propiedades de los poseedores de derechos de aguas o sus integridades físicas o psicológicas. En 1835, Filiberto Montt, escudado por Pedro Garretón y algunos soldados, despojó del cauce al señor P.A. León (Real Audiencia, vol. 1690: fj. 30v). Juan De las Cuevas acusó a Manuel Ramírez de destrozar los cercos que cubrían la acequia de Carrizalillos, fuente hídrica en disputa judicial, mientras de las Cuevas se encontraba de viaje (Real Audiencia, vol. 691: fj. 119). Como muestran estos incidentes, algunos particulares intentaron apropiarse del agua en varias ocasiones a través del uso de la fuerza. Sin embargo, no todo acto violento implicó destrucción de infraestructura hídrica. En 1780, Francisco Javier Errázuriz, con ayuda de Mateo de Toro y Zambrano, construyó una nueva acequia, ante el deseo de Cayetano Fontecilla de dividir un cauce que pasaba por el predio de Errázuriz, destruyendo una vía pública (Real Audiencia, vol. 755: fj. 50-112).

El despojo contra las mujeres viudas es un caso aparte, ya que el patrón que se repetía era la privación violenta de las fuentes de agua cuando su marido fallecía, mediante bloqueos o desvíos de aguas. En consecuencia, las viudas o herederas recurrían a la Real Audiencia para judicializar estos casos y obtener una resolución favorable. Juan Infante, por ejemplo, despojó del agua a Josefa Maldonado, reciente viuda de Pedro Barros, por lo que no podía regar su chacra en Renca (Real Audiencia, vol. 1690: fj. 198-229). La herencia provocó un vacío legal en el que se podían redefinir los derechos de uso de aguas, siendo esto usado por Infante para apropiarse del agua de Maldonado. María Antonia Andrade sufrió un intento de demolición de una muralla de su propiedad en 1750 por el corregidor Pedro José Lecaros, quien deseaba pasar agua hacia su predio (Real Audiencia, vol. 1713: fj. 2). Magdalena Negrete se querelló contra Antonio de Carvajal, Vicente Carrión y Gonzalo de Córdova, pues había sido despojada violentamente del agua 
de su inmueble (Real Audiencia, vol. 755: fj. 113-191). También hubo conflictos en los que una colectividad demandó a particulares, como el caso de Juan Antonio Araos y otros vecinos que demandaron a José de Ureta, quien deseaba construir un molino de trigo en Huechuraba, cerca de la acequia de los demandantes, lo que iba a ser perjudicial para sus cosechas (Real Audiencia, vol. 1275: fj. 218). Otro episodio lo protagonizaron unos comuneros de Renca que demandaron a Domingo Santiago y Pedro José de Prado en la década de 1800 por alterar el cauce de una acequia y dejar sin agua a dichos comuneros (Real Audiencia, vol. 1879: fj. 172).

La violencia verbal también fue perpetrada en los conflictos por apropiación del agua, a través del uso de malas palabras, descalificaciones e insultos proferidos, generalmente, por hombres hacia mujeres. El corregidor Nicolás de Silva tapó el cauce de una acequia en 1767, por lo que Manuela Cárdenas y Dominga Garay judicializaron esta resolución; Santiago Vivanco, abogado de Garay, señaló en este proceso que el señor de Silva había injuriado a su representada (Real Audiencia, vol. 1690: fj. 73-77). Un caso más grave sucedió en 1775: el Alcalde de segundo voto de San Juan de la Frontera Domingo Frías insultó a doña Petronila Cabrera y a otros cabildantes mientras se encontraban al frente de un cauce de agua en disputa, lo que conllevó la interposición de una causa criminal contra Frías por exceso de palabra, su encierro en el cabildo y posterior liberación previo pago de una fianza (Real Audiencia, vol. 1044: fj. 1-45).

La oposición y los desvíos de los pasos de agua fueron dos de los mecanismos de bloqueo al acceso más comunes en la Colonia, demostración del incumplimiento de los derechos de paso y del despojo del vital elemento. En algunas ocasiones, la oposición de los pasos de agua fue ordenada por una autoridad, sin haber pruebas de la realización de una consulta previa con los potenciales afectados. El caso relatado anteriormente de Manuela Cárdenas y Dominga Garay ilustra aquello, pues el corregidor Nicolás de Silva tapó la acequia utilizada por ambas, acto que secó en breve sus propiedades y la viña de Cárdenas (Real Audiencia, vol. 1690: fj. 73-77). La oposición de un paso de agua ordenado por una autoridad no solo afectó a los involucrados en un conflicto judicial, sino que se extendió a otros vecinos de propiedades contiguas que gozaban de una fuente hídrica común. En 1766 se desencadenó un conflicto por derecho de agua para una acequia en Vichuquén. El maestre de campo Rafael Parrado decidió tapar dicho paso ante la intención de Marcelo Jirón de sacar agua para su estancia. Luego, Carlos Saravia abrió la acequia para volver a proveerse del recurso hídrico (Real Audiencia, vol. 755: fj. 1-49).

Asimismo, hubo disputas entre particulares porque uno de ellos impedía el paso del agua que era aprovechado por el otro, incluso si existía un acuerdo anterior que sustentaba ese derecho. Joaquín de Bustamante adquirió un 
pasaje de acequia de agua para su estancia de San Francisco de Puangue, a través de una compra hecha a la sucesión de José Jofré; sin embargo, De Bustamante se querelló por haber sufrido un despojo del agua por medio de un taco en la acequia, que fue puesto por los albaceas de la propiedad de los herederos de Jofré (Real Audiencia, vol. 1690: fj. 153-197).

\section{La institucionalidad colonial ante los conflictos}

Si los conflictos por el agua se iniciaban mediante la violencia de algunos actores aprovechando su posición de privilegio dentro de la red hidrosocial (ya que como hemos visto en general eran personas con un estatus mayor las que violentamente se apropiaban del agua de otro de status menor), fue la institucionalidad desde arriba, a través del Cabildo, el Juez de Agua y un agrimensor, la que se encargó de distribuir el agua en las disputas por el preciado recurso, especialmente dentro de los predios dedicados a la cosecha de cultivos. Dichas autoridades buscaron, en un primer momento, reconstruir un estado inicial de distribución del suministro de agua hacia los terrenos, para luego relatar cuándo surgió el conflicto. Generalmente, este era originado cuando uno de los vecinos impedía el paso del curso de agua ya convenido, argumentando que el cauce atravesaba su propiedad. Un caso que ilustra lo anterior fue el enfrentamiento entre Cayetano Fontecilla y Francisco Javier Errázuriz sobre el mejor derecho a una servidumbre de aguas en Chuchunco (Real Audiencia, vol. 755: fj. 50-112). El ímpetu de Errázuriz por quedarse con el agua para regar sus cultivos fue tal que, junto a Mateo de Toro y Zambrano, como ya vimos, comenzaron a construir una acequia por el centro de la viña de Fontecilla, desecando su predio y rompiendo la vía pública (Real Audiencia, vol. 755: fj. 101v). Un conflicto similar ocurrió en 1809, entre las herederas de Francisco Javier Henríquez e Ignacia Fierro por la sucesión de un cuarto de solar que poseía una acequia. Fierro había cortado el agua hacia el terreno heredado, por lo que fue necesario dilucidar espacialmente la división de los predios gracias al agrimensor del Cabildo, Juan José Goycolea, quien distribuyó el agua a favor de las herederas Henríquez (Real Audiencia, vol. 767: fj. 1-67).

Este último caso también demostró que hubo litigios en que las autoridades coloniales ordenaron la repartición del agua de las acequias a través la construcción de acueductos o canales ramales. El agrimensor Goycolea midió ambos predios y sugirió que la herencia de Henríquez tuviese paso de agua, amparándose en que todo fundo urbano debía gozar de agua en las acequias (Real Audiencia, vol. 767: fj. 1-67). Fuentes coloniales incluso muestran que no todos los pasos de aguas estaban regulados legalmente desde un comienzo, lo cual podía originar disputas posteriores. Mateo Aedo construyó una acequia para sacar agua del río que pasó por las tierras de unos comuneros de Renca. Esto fue tolerado porque no interrumpió el 
abastecimiento del grupo de personas; sin embargo, Domingo Santiago y Pedro José de Prado alteraron el cauce de la acequia de los comuneros y los dejaron sin agua, por lo que estos últimos iniciaron un pleito legal cuya resolución final benefició a los señores Santiago y De Prado (Real Audiencia, vol. 1879: fj. 172).

Los alegatos de las partes en un juicio por derecho de uso agua contenían diversas consideraciones y develaban los intereses particulares en juego. El aprovechamiento del potencial productivo de una propiedad fue el argumento encontrado con más frecuencia en los litigios de la Real Audiencia, ya sea para defender una cuota de agua entregada con anterioridad, obtener derecho al uso de un cauce o para justificar un despojo o desviación hídrica. Las consideraciones económicas expuestas en estos juicios hicieron referencia, fundamentalmente, a actividades agrícolas y ganaderas desarrolladas en los predios. En una disputa sobre el mejor derecho al agua de una acequia de regadío, Magdalena Negrete aludió que su hacienda era muy antigua y estaba cultivando nuevos frutales y viñas (Real Audiencia, vol. 755: fj. 113-191). Juan Infante despojó del agua a Josefa Maldonado, quien poseía una chacarilla en Renca y usaba el recurso hídrico para regar su arboleda y unas viñas; el juicio giró en torno a la entrega de una cuota de extracción, por lo que la argumentación se basó en la sequía que azotaba a la zona y a la cantidad de sembrados que tenían Infante y Maldonado (Real Audiencia, vol. 1690: fj. 198-229). Juan Baptista de las Cuevas se opuso a la construcción de un ducto por Manuel Ramírez para regar sus terrenos, pues esa acequia "trasciende toda mi estancia por las partes más necesarias como son las majadas en que se encierra el ganado menor de que se me originan gravísimos perjuicios" (Real Audiencia, vol. 691: fj. 115). Así, la apelación a estas tareas refleja que la agricultura y ganadería fueron las dos actividades económicas de subsistencia más importantes en el Valle Central colonial chileno. Dadas sus condiciones extractivas, el agua era un elemento vital para determinar la supervivencia de las cosechas y animales dentro de una propiedad, por lo que contar con acceso hídrico fue un objetivo primordial de los propietarios.

El suministro de agua en un fundo, estancia, hijuela o predio podía obtenerse gracias a otra herramienta argumentativa: el uso de la tradición. La antigüedad, tanto de un terreno como de la acequia o canal que lo proveía de agua, fue una condición tan valorada por sus dueños que era menester defenderla. Gonzalo de Córdova, acusado de despojo violento de agua, señaló que su fundo de Negrete era antiguo, por lo que tomó el agua de la acequia en su legítimo derecho (Real Audiencia, vol. 755: fj. 113-191). Manuel Ramírez expuso que la bocatoma en disputa con Juan de las Cuevas era "tanta antigua [sic.] que no hay hombre en todo aquel partido que haga memoria de su apertura" (Real Audiencia, vol. 691: fj. 117). 
La evocación del bienestar social fue otra estrategia para defender una postura ante un conflicto por la utilización de los sistemas de riego. En algunos casos, se relacionó el uso del derecho de agua para desarrollar actividades con un potencial beneficio colectivo. Por ejemplo, José de Ureta deseaba construir un molino de trigo en una chacra de Huechuraba, por lo que buscó acceder a una acequia de propiedad de Juan Antonio Araos. Este último inició un pleito judicial porque dicho molino era perjudicial para sus cosechas, pero el pan era un bien necesario para Santiago, por lo que hubo testigos e informes favorables sobre la operatividad hídrica del molino (Real Audiencia, vol. 1275: fj. 218).

Asimismo, la necesidad de mantener derechos de uso sobre acequias y canales, o de aumentar las cuotas de extracción, fue vinculada con el provecho directo que obtenían u obtendrían grupos de personas que vivían en un mismo terreno. Melchora de Mena despojó del agua a Luisa Parras, porque consideró que el agua era de su propiedad. Parras solicitó en un juicio de 1705 que el agua pasase por su propiedad, obteniendo un fallo favorable porque poseía una encomienda. Felipe $V$ envió una Real Cédula en la que destacó la importancia de que las comunidades indígenas tuviesen acceso al agua (Real Audiencia, vol. 1690: fj. 231-272). Sin embargo, no todos los casos que abogaron por derechos de uso sistemas de aguas coloniales para grupos de personas tuvieron el mismo desenlace. El grupo de comuneros de Renca que mantuvo un conflicto judicial con Domingo Santiago y Pedro José de Prado por alterar curso de una acequia, solicitó la distribución equitativa del agua, pero la resolución final de la Real Audiencia dejó sin agua a la colectividad en 1828 (Real Audiencia, vol. 1879: fj. 172). En consecuencia, el tipo y el contenido de los argumentos expuestos por cada una de las partes no aseguraba una sentencia favorable; esto se debió, como se señaló al comienzo del capítulo anterior, a que la justicia colonial dirimía los conflictos de acuerdo con la naturaleza de cada caso particular.

\section{Resolución de los conflictos y alegatos posteriores}

No fue posible conocer las resoluciones de todos los juicios por el agua hallados en el Fondo de Real Audiencia del Archivo Nacional. Entre las causas que explican esta limitante se encuentran el deterioro natural de las fuentes escritas a lo largo del tiempo, o la pérdida o destrucción de estos antecedentes de la época colonial por diversos motivos. A pesar de lo anterior, hay vestigios que nos entregan algunas determinaciones judiciales de la Real Audiencia ante conflictos hídricos en el Valle Central chileno. A partir de ellas se plantea que las resoluciones jurídicas fueron variadas, lo que explica la casuística de las decisiones judiciales en la Colonia. Los oidores de la Real Audiencia intentaron conciliar a ambas partes a través de la entrega de cuotas de agua, ya fuesen equitativas o asimétricas. El 
reparto igualitario entre los litigantes fue decidido en el caso de Magdalena Negrete contra Gonzalo de Córdova, Antonio de Carvajal y Vicente Carrión, quienes bloquearon el paso del agua hacia la hacienda frutícola de Negrete (Real Audiencia, vol. 755: fj. 167). Mientras que la segunda fue entregada a Josefa Maldonado, que fue despojada del agua por Juan Infante luego del deceso de su esposo Pedro Barra; la corte determinó que Maldonado tenía derecho a extraer toda el agua de Infante durante la mitad de una jornada cada ocho días, además de instalar una media regadora (Real Audiencia, vol. 1690: fj. 227).

La Real Audiencia también ordenó la construcción de nueva infraestructura hídrica, lo que implicó cambios en los sistemas de riego en conflicto. Esto sucedió en 1750, al aprobar la solicitud del corregidor Pedro José Lecaros de efectuar un desvío para que la mitad del caudal de agua de una acequia pasase por su predio en Santiago (Real Audiencia, vol. 1713: fj. 1-43). Algunas veces se buscó la construcción de nuevos cauces para mejorar la distribución del agua de una acequia principal, como en el conflicto de Petronila Cabrera contra Domingo Frías (Real Audiencia, vol. 1044: fj. 56), y en el de las herederas de Francisco Henríquez, que lograron la construcción de canales ramales para proveerse del agua que pasaba por la acequia de Ignacia Fierro (Real Audiencia, vol. 767: fj. 1-67). Sin embargo, la Real Audiencia no acogió todas las solicitudes de nuevos conductos hídricos, pues en 1777 sentenció que no había lugar a la solicitud de Manuel Ramírez de abrir una nueva acequia a través de la estancia de Juan de las Cuevas en Colchagua (Real Audiencia, vol. 691: fj. 272). Incluso, la Real Audiencia dictaminó sentencias drásticas para resolver conflictos de uso de agua, como a inicios del siglo XIX cuando los oidores despojaron del vital elemento a los comuneros de Renca en conflicto con Domingo Santiago y Pedro José de Prado (Real Audiencia, vol. 1879: fj. 172-).

Tal y como en relación con los argumentos esgrimidos por los actores en conflicto y las resoluciones hechas por la Real Audiencia, no fue posible conocer todas las respuestas de los interesados al desarrollo de los juicios y a los dictámenes del tribunal de justicia. Esta limitación impide estudiar cuál fue la reacción más frecuente de los particulares en conflicto, así como también cuáles fueron todos los tipos de réplicas que surgieron luego de una sentencia sobre aguas. Pese a lo anterior, a continuación se muestran algunas respuestas ante una resolución judicial que no respaldó los intereses de las personas, las que se tradujeron en desacatos y apelaciones a los fallos.

La nulidad fue una herramienta jurídica que, en los asuntos referidos a sistemas de agua, fue utilizada principalmente para dejar sin efecto una determinación que redujo, limitó o detuvo el caudal hídrico, y que, en algunos casos, derivó en extracciones ilegales de agua. En 1766 hubo un conflicto entre Marcelo Jirón y Carlos Saravia por un derecho de agua para regar 
una estancia de Jirón en Vichuquén; el maestro de campo Rafael Parrado sentenció tapar la acequia en cuestión, afectando a todos los vecinos por igual y provocando que Saravia volviese a abrir el conducto de agua y que Jirón pidiere la nulidad del juicio (Real Audiencia, vol. 755: fj. 1-49). En otros casos, la nulidad vino acompañada de un desacato manifestado en forma de rebeldía, como lo hizo Ignacia Fierro en 1814. Fierro solicitó la anulación de la sentencia que ordenó la construcción de canales ramales para la sucesión de Francisco Javier Henríquez, que serían surtidos de agua por la acequia de los padres de Ignacia Fierro. Esta última se declaró en rebeldía y no dio paso de agua para las herederas de Henríquez, pero la Real Audiencia no acogió su solicitud (Real Audiencia, vol. 767: fj. 1-67).

A pesar que el corregidor Pedro José Lecaros intentó derribar previamente la pared de la propiedad de María Antonia Andrade para acceder al agua deseada, la Real Audiencia aprobó su solicitud de construir un desvío para que pasase por su propiedad la mitad del agua que llevaba la acequia de Andrade. La réplica de ella fue retrasar las obras del nuevo canal a través de una herramienta jurídica distinta a la nulidad: la apelación de la sentencia (Real Audiencia, vol. 1713: fj. 1-43). Pese a que se desconoce si pudo revertir la edificación de la acequia, se sugiere que pudo haberse postergado el cumplimiento de la sentencia de la Real Audiencia, pues María Andrade apeló en varias ocasiones a dicho dictamen. Un caso en el que se acogió favorablemente una apelación fue hecha por P. A. León, luego que Filiberto Montt le tapase el paso de agua en la Quebrada del Trapiche. El juez de Casablanca falló a favor del señor Montt; sin embargo, León apeló la resolución en la Real Audiencia y aludió a los vínculos personales de Filiberto Montt con el juez de la localidad. Este caso prueba que las apelaciones podían originar actos violentos contra quienes las realizaban, pues el Gobernador de Casablanca, el juez local aludido y algunos soldados se dirigieron a la propiedad de León para quitarle el agua (Real Audiencia, vol. 1690: fj. 2-47).

\section{Consideraciones finales}

Nuestra metodología se sustentó en el concepto de la variación de escalas. Ella muestra la inconmensurabilidad entre distintas dimensiones (Ricoeur, 2008), lo cual permite ver fenómenos a distintas escalas y expandir las posibilidades de las ciencias sociales gracias al enfoque microhistórico (Iggers, 2012). Ahora bien, explorar el nivel "micro" y estudiar cómo se vivieron efectivamente los conflictos por el agua, no significa caer en la simple crónica de lo particular y renunciar a la posibilidad de elaborar generalizaciones, sino que requiere de una nueva forma de entender la manera cómo se puede leer el contexto social. Desde el funcionalismo y otras tradiciones "macro", el contexto social se ha visto como la forma en la que se puede abordar los 
casos anómalos al sistema, explicando su significado oculto y por lo mismo reducibles en última instancia a la totalidad. Mientras que la microhistoria, al poner énfasis en hechos aparentemente anómalos o carentes de significación, muestra cómo estos cobran "sentido al revelarse las incoherencias ocultas de un sistema social aparentemente unificado" (Levi, 1993: 138).

Estas escalas son denominadas por Tvedt (2010) como "distintos niveles del sistema de aguas". En cuanto al primer nivel, el físico, podemos afirmar que al llegar los españoles a un clima mediterráneo o semiárido con ciclos de lluvias y sequías impredecibles, el control del agua era un instrumento de dominación fundamental, cuestión que entendieron bien las huestes conquistadoras lideradas por Pedro de Valdivia. El segundo nivel es el despliegue físico de la red hidrosocial, es decir, cómo las comunidades se hacen del agua. En el caso de la colonia, podemos ver que se desplegaron una serie de acequias y canales que permitieron la consolidación de la economía del reino a lo largo del Valle Central. De todos modos, estas modificaciones al nivel material del agua fueron limitadas dentro de la Colonia, tal como dejó de testimonio la centenaria construcción del Canal del Maipo, obra hidráulica que fue terminada en la República y cambió definitivamente este segundo nivel. Finalmente, el tercer nivel, referido a la institucionalidad y los tipos de relaciones de las personas con el agua, fue el enfoque de nuestra investigación, pues en el primer capítulo analizamos su constitución y el segundo su consolidación.

En las pugnas por el agua del tercer nivel se condensan las relaciones sociales en sus distintas dimensiones (estatus, patrimonio, género, poder institucional y poder local) ocurridas durante la Colonia en la actual Zona Central de Chile, confirmando lo que múltiples otras investigaciones han abordado para otras latitudes del mundo: el agua es una forma imprescindible de aproximarnos a las sociedades de distintos lugares (Hunt, 2007). Lees (1986) aplica un esquema de negociación que analiza distintos casos alrededor del mundo en el siglo XX (Israel, Sudan y Kenia), desde la premisa que la agricultura local es, en muchos casos, incompatible con la administración de los recursos, específicamente el agua, hecha por la burocracia centralizada. Así, las reglas estandarizadas de la burocracia obligarían a los granjeros a comportarse de manera inadecuada a su medio o a romper las reglas ante los ojos de la administración central. Las mediaciones entre el poder central y el local, en un contexto colonial premoderno, presentan ejemplos tan diversos como el Mezzogiorno italiano en siglo XIX (Bevilacqua, 1986) y el Egipto Otomano del siglo XVII (Mikhail, 2010). Como vimos en el segundo apartado, esta negociación con la burocracia ocurrió al inicio del periodo colonial durante el asentamiento de los españoles en Chile, lo que llevó a compatibilizar las reglas por el agua venidas desde la Corona con la realidad de un territorio "nuevo", sistema que finalmente funcionó y tuvo el poder real para resolver conflictos. 
Finalmente, en el último apartado analizamos las causas y las formas de los conflictos por el agua entre distintos actores, destacándose el despojo mediante violencia. Revisamos las formas de la violencia física o verbal y la destrucción de infraestructuras públicas y propiedades particulares. Los actores en pugna por el derecho de uso de agua desplegaron estrategias legales, como el inicio de un juicio en juzgados locales o la apelación de resoluciones de primera instancia en la Real Audiencia. La Real Audiencia actuó bajo la premisa de distribuir el agua en distintos grados de proporcionalidad. Pese a lo anterior, las sentencias eran decididas según cada caso particular, pues hubo conflictos con un origen similar que tuvieron fallos distintos.

\section{Referencias bibliográficas}

\section{Fuentes primarias}

\section{a) Archivos}

Actas del Cabildo de Santiago, Archivo Nacional, Chile, 1541-1802.

Fondo Real Audiencia, Archivo Nacional, Chile, 1691-1828.

b) Impresos y documentos

De Lillo, G. (1605). "Mensura general de tierras de Ginés de Lillo: 1602-1605", en Aniceto Almeyda, Colección de historiadores de Chile y de documentos relativos a la historia nacional. Tomo XLIX. Santiago: Imprenta Universitaria.

\section{Fuentes secundarias}

a) Artículos de libros y revistas

Agüero, A. (2006). "Las categorías básicas de la cultura jurisdiccional", en Marta Lorente (coord.), De justicia de jueces a justicia de leyes: hacia la España de 1870. Madrid: Consejo General del Poder Judicial.

Banister, J.M. (2014). "Are you Wittfogel or against him? Geophilosophy, hydrosociality, and the state", en Geoforum, № 5, pp. 205-214

Bender, M. (2008). "`For More and Better Water, Choose Pipes!> Building Water and the Nation on Kilimanjaro, 1961-1985", en Journal of Southern African Studies, Vol. 34, № 4, pp. 841-859.

Bevilacqua, P. (1986). "Acque e bonifiche nel Mezzogiorno nella prima metà dell'Ottocento", en Studi Storici, Vol. 27, № 2, pp. 335-357. 
Bichsel, C. (2016). "Water and the (Infra-)Structure of Political Rule: A Synthesis", en Water Alternatives, Vol. 9, № 2, pp. 356-372.

Dougnac, A. y J. Barrientos (1991). "El derecho de aguas a través de la jurisprudencia chilena de los siglos XVII y XVIII", en Revista de Estudios Histórico-Jurídicos, No 14, pp. 101-136.

Hunt, R. (1988). "Size and the structure of authority in canal irrigation systems", en Journal of Anthropological Research, Vol. 44, № 4, pp. 335-355.

Hunt, R. (2007). "Communal irrigation A comparative perspective", en Peter Boomgaard (editor), A World of Water. Leiden: KItIV Press.

Kelly, W. (1983). "Concepts in the anthropological study of irrigation", en American Anthropologist, Vol. 85, № 4, pp. 880-886.

Lees, S. (1986). "Coping with Bureaucracy: Survival Strategies in Irrigated Agriculture", en American Anthropologist, Vol. 88, №3, pp. 610-622.

Lees, S. (1989). "On Irrigation and the Conflict Myth", en Anthropology, Vol. $30, N^{\circ} 3$, pp. 343-344.

Levi, G. (1993). "Sobre la microhistoria", en Peter Burke (editor), Formas de hacer historia. Madrid: Alianza.

Mikhail, A. (2010). "View from ottoman fayyum", en International Journal of Middle East Studies, Vol. 42, № 4, pp. 569-590.

Muñoz, G. (2000). "La servidumbre de acueducto en el derecho indiano", en Revista de Derecho Administrativo Económico, Vol. 3, Nº 6, pp. 413-424.

Palerm, J. (1995). "Sistemas hidráulicos y organización social: La polémica y los sistemas de riego del Acolhuacan septentrional", en Estudios Mexicanos, Vol. $11, N^{\circ} 2$, pp. 163-178.

Sánchez-Rodríguez, M. (2015). "Agua, horticultura y urbanismo en una ciudad americana. Santiago de Chile en la época virreinal", en Agua y Territorio, № 5, pp. 38-53.

Stenberg, R. y G. Sotomayor (2012). "Mapocho Incaico", en Boletín del Museo Nacional de Historia Natural, № 61, pp. 85-149.

Tvedt, T. (2010). "'Water Systems', Environmental History and the Deconstruction of Nature", en Environment and History, Vol. 16, № 2, pp. 143-166.

Vidal-Naquet, P. (1964). "Histoire et idéologie: Karl Wittfogel et le concept de mode de production asiatique", en Annales. Économies, Sociétés, Civilisations, Vol. 19, № 3, pp. 531-549. 
Von Benda-Beckmann, F. (2007). "Contestations over a life-giving force Water rights and conflicts, with special reference to Indonesia", en Peter Boomgaard (editor), A World of Water. Leiden: KItIV Press.

Von Wobeser, G. (1993). "El agua como factor de conflicto en el agro novohispano 1650-1821", en Estudios de Historia Novohispana, Vol. 13, № 13 , pp. 135-146.

\section{b) Libros}

De Ramón, A. (2000). Santiago de Chile: (1541-1991): historia de una sociedad urbana. Santiago: Editorial Sudamericana.

Deleuze, G. y F. Guatarri (2004). Mil Mesetas: Capitalismo y esquizofrenia. España: Pre-Textos.

Falabella, F., M. Uribe, L. Sanhueza, C. Aldunate y J. Hidalgo (2016). (Editores) Prehistoria en Chile: desde sus primeros habitantes hasta los incas. Santiago: Editorial Universitaria.

Fagan, B. (2012). Elixir: A History of Water and Humankind. London: Bloomsbury Press.

Góngora, M. y J. Borde. (1956). Evolución de la propiedad rural en el valle del Puangue. Santiago: Universitaria.

Góngora, M. (1970). Encomenderos y estancieros: estudios acerca de la constitución social aristocrática de Chile después de la conquista 1580-1660. Santiago: Universidad de Chile.

Iggers, G. (2012). La historiografía del siglo XX: desde la objetividad científica al desafío posmoderno. Santiago: Fondo de Cultura Económica.

Nathan, E. (2007). Lost Waters: A History of a Troubled Catchment. Melbourne: Melbourne University Press.

Ricoeur, P. (2008). La memoria, la historia y el olvido. Buenos Aires: Fondo de Cultura Económica.

Silva, F. (1962). Tierras y pueblos de indios en el reino de Chile: esquema histórico - jurídico. Santiago: Pontificia Universidad Católica de Chile.

Stewart, D. (1970). El Derecho de Aguas en Chile. Santiago: Editorial Jurídica de Chile.

Wittfogel, K. (1966). Despotismo oriental: Estudio comparativo del poder totalitario. Madrid: Guadarrama.

Zamora, J. (1844). Biblioteca de legislación ultramarina en forma de diccionario alfabético. Tomo $2^{\circ}$ - Letras B, C. Madrid: Imprenta de Alegría y Charlain. 